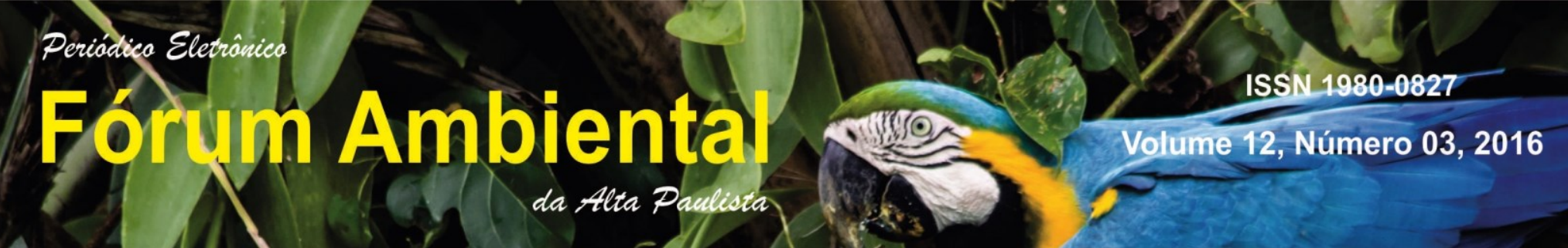

\title{
A Logística Reversa de Embalagens Vazias de Agrotóxicos junto a produtores rurais do Interior do Estado de São Paulo
}

The Reverse Logistics of Agrochemical Packaging with the farmers in interior region of the state of São Paulo

La logística inversa de envases de agroquímicos con los agricultores de la región interior del estado de Sao Paulo

Maurício Dias Marques

Mestrando em Agronegócio e Desenvolvimento, UNESP, Brasil Membro do Grupo de Pesquisa em Educação Ambiental, PGEA, UNESP. mdmarques1985@gmail.com

Silvia Cristina Vieira

Mestre em Agronegócio e Desenvolvimento, UNESP, Brasil Membro do Grupo de Pesquisa em Educação Ambiental, PGEA, UNESP.

tinavieiragomes@hotamail.com

Sérgio Silva Braga Junior

Professor Doutor, UNESP, Brasil sergio@tupa.unesp.br 


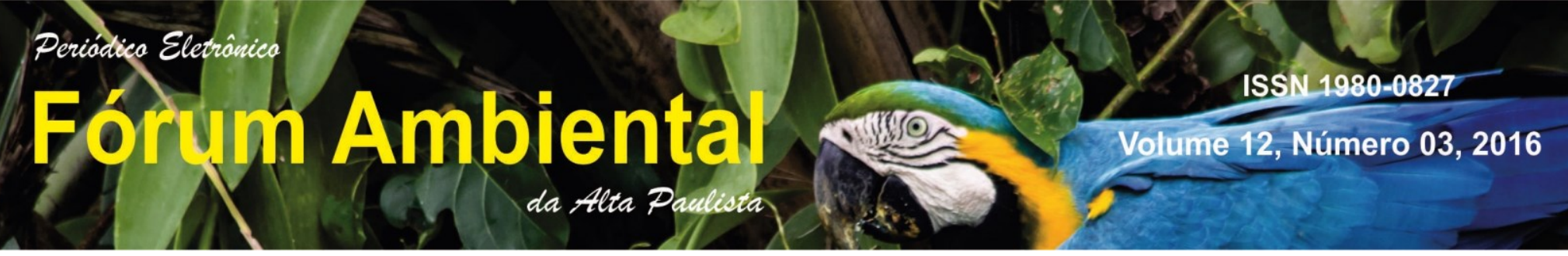

\section{INTRODUÇÃO}

O uso de agrotóxicos no Brasil tornou-se intenso a partir da década de 1960. É um dos principais consumidores mundiais de agrotóxicos, aplicando-os em maior grau na agricultura. Os retornos econômicos e agronômicos ao produtor rural são vistos como vantagens, mas, por outro lado, degradação ambiental e risco à saúde humana são desvantagens que os agrotóxicos proporcionam. Esses problemas de saúde pública, demandam a implantação de um sistema de vigilância da saúde de populações expostas a agrotóxicos (OPAS / OMS, 2010).

Relativamente às embalagens dos agrotóxicos, existem restrições legais relacionadas ao meio ambiente e aos fatores econômicos (SHIBAO; MOORI; SANTOS, 2010). A norma ABNT-NBR 10.004 de 2004 enquadra as embalagens vazias de agrotóxicos na categoria de resíduos perigosos pelo seu potencial de toxicidade e contaminação.

Para Cometti e Alves (2010), se as embalagens forem descartadas no meio ambiente podem contaminar o solo e lençóis freáticos; se reutilizadas como utensílios domésticos para condicionar água e alimentos, podem provocar contaminação humana.

Por essa razão, conforme estudado por Marques, Braga Junior e Cataneo (2015), a legislação brasileira vem, ao longo dos anos, tratando de diretrizes e restrições quando a utilização e descarte dessas embalagens. Atualmente aplica-se a responsabilidade solidária entre aqueles que direta e indiretamente praticaram a conduta lesiva ao meio ambiente.

A maneira que a lei encontrou de implantar essa responsabilidade solidária é a transferência das embalagens do consumo ao produtor dos agrotóxicos, por meio da logística reversa, conforme estabelecido na Política Nacional de Resíduos Sólidos - PNRS apontada na Lei 12.305/2010, regulamentada pelo Decreto 7.404/2010, condição que já havia sido sistematizada na Lei dos Agrotóxicos (Lei 9.974/2000), regulamentada pelo Decreto 4.074/2002 (BRASIL, 2010; 2000; 2002).

A Lei dos Agrotóxicos impõe responsabilidades e competências divididas entre todos os agentes atuantes no uso dos defensivos agrícolas. Ao produtor rural (que utiliza o agrotóxico como consumidor final) coube a responsabilidade da tríplice lavagem e devolução das embalagens pós-consumo; aos comerciantes, a responsabilidade de dispor de local adequado para recebimento das embalagens e/ou indicar nas notas fiscais de venda os locais de devolução; ao fabricante, a responsabilidade de recolher e dar a destinação final adequada às embalagens; e ao governo, a responsabilidade de fiscalizar e promover, junto com os fabricantes, a orientação técnica e educação ambiental.

Todas essas ações de responsabilidades se desenvolvem por meio da logística reversa, com início no produtor rural. 


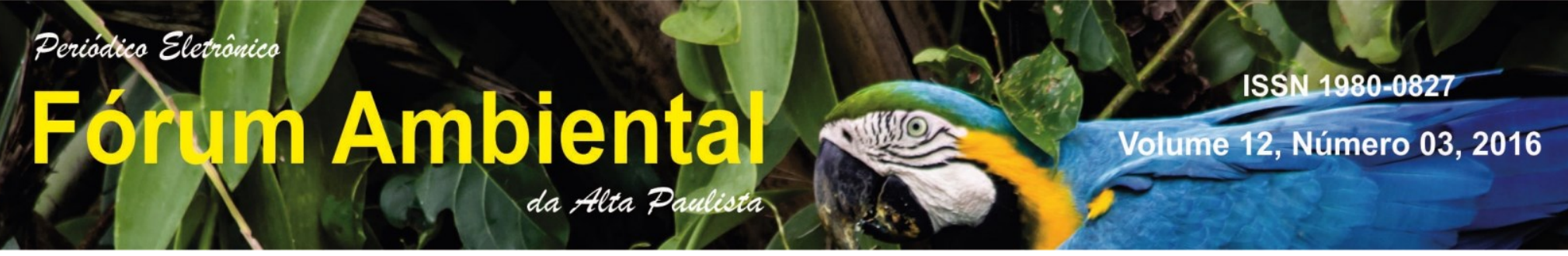

\section{OBJETIVO}

A presente pesquisa teve como objetivo entender o funcionamento prático da logística reversa das embalagens vazias de agrotóxicos, no interior paulista, no município de Tupã e seus entornos, diante das determinações da legislação vigente.

São objetivos específicos: a identificação da legislação que disciplina a logística reversa de devolução de embalagens vazias de agrotóxicos em seu primeiro estágio, junto aos produtores rurais; a coleta de informações do procedimento da logística reversa, junto ao produtor rural, como primeiro elo dessa cadeia logística; a verificação da contribuição do usuário do agrotóxico na preservação do meio ambiente e desenvolvimento sustentável, por meio do cumprimento da legislação da logística reversa de embalagens vazias de agrotóxicos.

\section{METODOLOGIA}

Quanto à abordagem, utiliza-se a metodologia qualitativa, por meio da qual o investigador entra em contato direto com o indivíduo ou grupos humanos, com o ambiente e com a situação que está sendo investigada, permitindo um contato de perto com os informantes (MARCONI; LAKATOS, 2004).

Trata-se de uma pesquisa descritiva e exploratória. É descritiva por narrar situações e buscar relações entre os elementos que compõem a pesquisa. É exploratória por familiarizar-se com o fenômeno, obtendo uma nova percepção do mesmo. Além disso, flexibiliza o planejamento para possibilitar a consideração dos mais diversos aspectos do problema (CERVO; BERVIAN, 2003).

A técnica de coleta de dados harmoniza vários instrumentos. A priori, pesquisa bibliográfica no contexto da logística reversa das embalagens vazias de agrotóxicos, com enfoque na disposição legal e obstáculos encontrados pelo produtor rural. Num segundo momento, coleta de dados por meio de aplicação de formulários semiestruturados junto a 48 produtores rurais de Tupã e circunvizinhança, no interior do estado de São Paulo, em período delimitado entre abril a maio de 2015 e janeiro de 2016, visando a busca de informações sobre sua predisposição em devolver as embalagens, como estabelecido na legislação e os gaps encontrados para que a devolução ocorra dentro dos parâmetros legais.

A análise desta pesquisa de campo considerou a triangulação dos resultados dos formulários sobrepostos ao conteúdo bibliográfico e à legislação pesquisada.

\section{FUNDAMENTAÇÃO TEÓRICA}

Para entender o mecanismo da responsabilidade do produtor rural para a devolução das embalagens vazias de agrotóxicos no primeiro elo da cadeia da logística reversa, faz-se necessário entender a logística reversa como imposição da legislação.

A Política Nacional de Resíduos Sólidos - Lei 12.305/2010 estabeleceu como instrumento de desenvolvimento econômico e social a implantação de sistemas de logística reversa, 


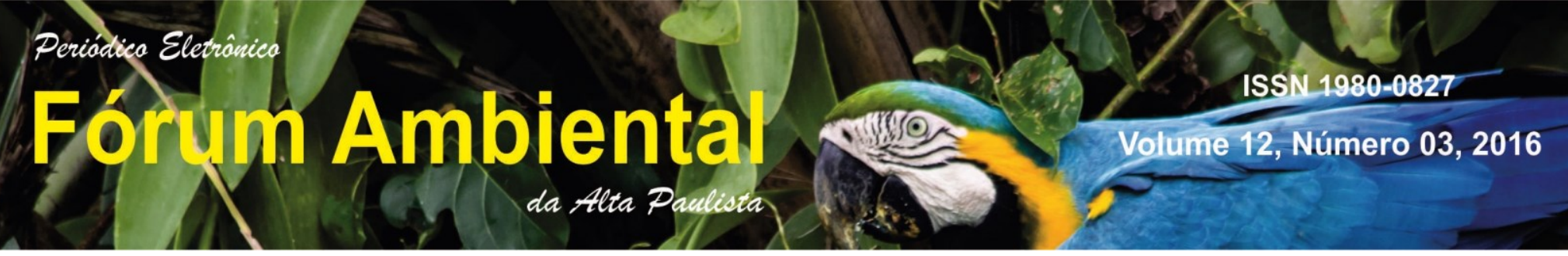

imputando a responsabilidade do pós-consumo aos fabricantes, importadores, distribuidores, comerciantes e consumidores (MOURÃO e SEO, 2012; BRASIL, 2010).

Ficou definido no inciso XII do artigo 3o dessa lei, que "logística reversa é o instrumento de desenvolvimento econômico e social caracterizado por um conjunto de ações, procedimentos e meios destinados a viabilizar a coleta e a restituição dos resíduos sólidos ao setor empresarial, para reaproveitamento, em seu ciclo ou em outros ciclos produtivos, ou outra destinação final ambientalmente adequada" (BRASIL, 2010).

Em sentido amplo, a logística reversa compreende todas as operações relacionadas com a reutilização de produtos e materiais, o que engloba todas as atividades logísticas de coletar, desmontar e processar produtos e/ou materiais e peças usadas a fim de assegurar uma recuperação sustentável (LEITE, 2003).

De acordo com Shibao, Moori e Santos, 2010, Logística Reversa pode ser definida como:

o processo de planejamento, implantação e controle eficiente e eficaz dos custos, dos fluxos de matérias-primas, produtos em estoque, produtos acabados e informação relacionada, desde o ponto de consumo até um ponto de reprocessamento, com o objetivo de recuperar valor ou realizar a disposição final adequada do produto.

Freitas, Hoppe e Murini (2015), colocam que a logística reversa é um instrumento ligado ao consumo sustentável, eis que propicia retorno dos produtos ao processo produtivo, tornando possível a transformação em matéria-prima.

A logística reversa completa o caminho para reciclagem dos objetos "sem valores" associados ao produto principal e as empresas têm encontrado oportunidades de recuperar os custos de produção, ganhando dinheiro. A logística envolve a cadeia de produção, da matéria-prima até o consumidor final; a logística reversa inicia-se no ponto de consumo e termina na origem. (SEHNEM, SIMIONI E CHIESA, 2009).

Por sua vez, a logística reversa das embalagens de defensivos agrícolas, tem sua importância no sentido de diminuir o "lixo" nas propriedades rurais, que pode impactar significativamente o meio ambiente causando danos nocivos à saúde humana e à natureza.

Segundo Souza e Gebler (2013), entre os principais fatores determinantes do destino final das embalagens vazias de agrotóxicos encontra-se o tipo de material que as constitui e sua periculosidade ao meio ambiente, isso função da possibilidade de realização do processo de tríplice lavagem no momento de preparo da calda, indicada pela Norma 10.004 da ABNT (2004), com duas classes de resíduos: I - perigosos; II - não perigosos. As embalagens rígidas vazias de agrotóxicos, que podem ser objeto da tríplice lavagem, são classificadas como resíduo não perigoso (classe II) para fins de manuseio, transporte e armazenagem. As embalagens que acondicionam produtos na forma sólida (em grânulo ou pó), destinados ao tratamento de sementes ou cuja forma de aplicação exija volume ultra-baixo de água (menos de 20 litros por hectare) impedindo a tríplice lavagem, pertencem à classe $\mathrm{I}$.

Para chegar ao destino final há que se percorrer a logística reversa. A logística reversa das embalagens vazias de agrotóxicos, especificamente, é determinada pela legislação, como se 


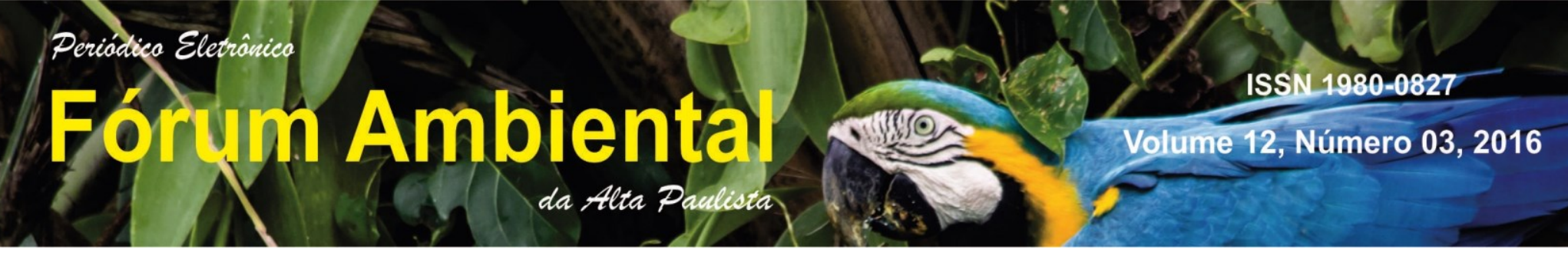

pode observar nos parágrafos 20 e 5을 do artigo 6 transcritos abaixo, da Lei 7.802/89, alterada pela Lei 9.974/2000:

\begin{abstract}
$\S 2$ o Os usuários de agrotóxicos, seus componentes e afins deverão efetuar a devolução das embalagens vazias dos produtos aos estabelecimentos comerciais em que foram adquiridos, de acordo com as instruções previstas nas respectivas bulas, no prazo de até um ano, contado da data de compra, ou prazo superior, se autorizado pelo órgão registrante, podendo a devolução ser intermediada por postos ou centros de recolhimento, desde que autorizados e fiscalizados pelo órgão competente. $\S 5$ o As empresas produtoras e comercializadoras de agrotóxicos, seus componentes e afins, são responsáveis pela destinação das embalagens vazias dos produtos por elas fabricados e comercializados, após a devolução pelos usuários, e pela dos produtos apreendidos pela ação fiscalizatória e dos impróprios para utilização ou em desuso, com vistas à sua reutilização, reciclagem ou inutilização, obedecidas as normas e instruções dos órgãos registrantes e sanitário-ambientais competentes (BRASIL, 2000).
\end{abstract}

Sehnem, Simioni e Chiesa (2009), registram que o processo pelo qual se desencadeia o fluxo de reciclagem de embalagens de agrotóxicos vazias é o seguinte: Compra do produto; Aplicação na lavoura; Lavagem da embalagem; Inutilização da embalagem; Devolução na unidade de recebimento; Prensagem da embalagem; Transporte para o destino final; Etapa da reciclagem; Produção do artefato. Com o destino correto, para um lugar adequado, as embalagens deixam de ser jogadas a céu aberto, no meio ambiente. Assim, há benefícios proporcionados por esse tipo de logística reversa proporcionando uma melhor preservação do meio ambiente, benefícios para toda a sociedade e para as futuras gerações.

Apegando-se aos estudos de Cometti (2009); Melo et al. (2012); Cantos, Miranda e Licco (2008); Grutzmacher et al. (2006); Leite (2009) e Faria e Pereira (2012), as responsabilidades dos produtores rurais perante a logística reversa seriam:

Aos usuários dos agrotóxicos - agricultores (consumidores):

- preparar as embalagens vazias para devolvê-las (embalagens rígidas laváveis: efetuar a tríplice lavagem ou lavagem sob pressão; inutilizar, perfurando, para evitar o reaproveitamento);

- para as embalagens rígidas não laváveis: mantê-las intactas, adequadamente tampadas e sem vazamento; embalagens flexíveis contaminadas: acondicioná-las em sacos plásticos padronizados;

- armazenar, temporariamente, as embalagens vazias em local adequado na propriedade;

- transportar e devolver as embalagens vazias, com suas respectivas tampas, no estabelecimento onde foi adquirido o produto ou na unidade de recebimento indicada na nota fiscal, no prazo de até um ano contado da data de sua compra;

- manter em seu poder os comprovantes de entrega das embalagens e a nota fiscal de compra do produto por um ano.

\title{
A logística reversa iniciada com o produtor rural
}

Para Bressan et al. (2014), apesar da legislação determinar a obrigação do agricultor em devolver as embalagens pós consumo, ela não determina como será aplicada. Até o ano de 


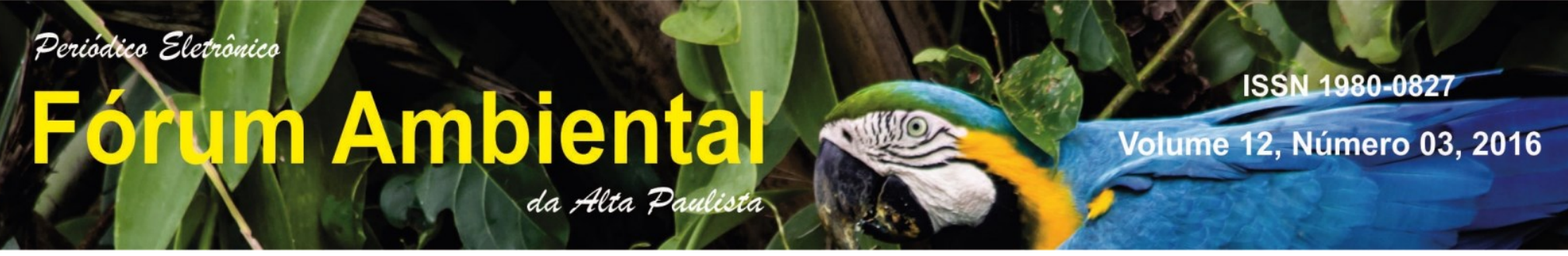

2000 não existia ainda nenhuma entidade que viabilizasse o processo de devolução das embalagens. Foi criado o INPEV (Instituto Nacional de Processamento de Embalagens Vazias), para possibilitar melhor atender a exigência legal e facilitar a operacionalização da logística reversa.

Esse instituto é uma entidade sem fins lucrativos destinado a gerir o processo de destinação de embalagens vazias de agrotóxicos, dar apoio e orientação à indústria, canais de distribuição e agricultores no cumprimento das responsabilidades definidas pela legislação, promover a educação e a consciência de proteção ao meio ambiente e à saúde humana e apoiar o desenvolvimento tecnológico de embalagens de agrotóxicos e afins (SEHNEM; SIMIONI; CHIESA, 2009)

Com sede em São Paulo, Capital, o INPEV gerencia o chamado Sistema Campo Limpo, que tem em sua composição quatro grupos, sendo: fabricantes, comércio, poder público e os agricultores. De acordo com Sehnem; Simioni e Chiesa (2009), o INPEV é mantido integralmente pela indústria fabricante, tem como principais atividades o transporte das embalagens vazias, ou seja, a logística reversa, até o destino final (reciclagem ou incineração), o fomento à criação e gerenciamento de unidades de recebimento de embalagens e a coordenação de campanhas educativas para agricultores.

Segundo Relatório de Sustentabilidade de 2014, do INPEV, houve ampliação da estrutura física e da capilaridade de recebimento, totalizando 415 unidades de recebimento. 0 Sistema Campo Limpo destinou corretamente 94\% das embalagens primárias (42.646 mil toneladas de embalagens), sendo $91 \%$ delas para reciclagem e $9 \%$ para incineração.

Esse sistema em 2014 gerou 1,5 mil empregos diretos, possuía 156 mil m² de área construída, com 113 centrais e 302 postos de recebimento, 4,8 mil recebimentos itinerantes e, nos 12 anos de atuação, mais de 320 mil toneladas de embalagens tiveram a destinação correta.

Portanto, no âmbito formal, deixa-se transparecer que há condições de execução da logística reversa das embalagens vazias de agrotóxicos.

\section{RESULTADOS}

Entende-se, portanto, que a política pública da logística reversa das embalagens vazias de agrotóxicos, conforme a legislação, atribui responsabilidade ao produtor rural (usuário final do agrotóxico) e que os comerciantes contam com o apoio do INPEV para que as embalagens cheguem à indústria fabricante do agrotóxico para o destino final adequado.

Todavia, alguns estudos têm dado a conhecer que toda essa estrutura parece não ser capaz de atender todos os pontos de propriedades rurais que utilizam os agrotóxicos, ocasionando certos problemas.

Para exemplificar, pesquisa realizada Cometti e Alves (2010), observou que a distância das unidades de recebimento é uma das queixas mais recorrentes entre os agricultores. De Lima et al. (2009), relatam que na região sul do Rio Grande do Sul, onde há uma central de recebimento do INPEV, dos 135 entrevistados, 80,8\% guardam as embalagens para posterior 
recolhimento a ser realizado pela prefeitura ou pelas revendas de agrotóxicos, percebendo-se descasos e abusos. Investigação do IBGE em 2002, relata que de 5.560 municípios brasileiros, 978 descartavam embalagens de agrotóxicos em vazadouros a céu aberto e que o descarte seguro das embalagens não é observado em todo o País (IBGE, 2005).

Tendo em vista o apontamento desses dados negativos, ganha atenção os resultados obtidos por esta pesquisa, realizada com 48 produtores rurais respondentes no interior do estado de São Paulo, município de Tupã e adjacências.

Importante mencionar que o presente trabalho é parte de uma pesquisa maior, onde foi aplicado formulário aos produtores rurais contendo 17 proposições (questões fechadas) em escala de Lickert (com 5 valores em escala de importância) e 02 questões abertas, para identificar a percepção e o comportamento dos mesmos perante a legislação do retorno das embalagens vazias de agrotóxicos.

Este artigo utiliza parte do questionamento realizado, mais especificamente sobre a realização ou não da devolução das embalagens vazias dos agrotóxicos, a informação que o produtor tem de sua responsabilidade e a atenção do poder público no tocante a fiscalização. Assim é que os resultados demonstram análise apenas das seguintes questões:

Questões fechadas:

P-01 - Sempre sou informado que existe a obrigatoriedade de devolver as embalagens vazias de defensivos agrícolas.

P-08 - Sempre devolvo as embalagens no endereço indicado na nota fiscal de compra.

P-12 - Sempre faço a devolução das embalagens vazias nos revendedores onde compro.

P-15 - Recebo com regularidade fiscalização sobre o armazenamento, transporte e devolução das embalagens vazias de defensivos agrícolas.

Questão aberta: De quanto em quanto tempo faz a devolução das embalagens?

As respostas dadas às questões P-12 (devolução das embalagens nos revendedores) e P-08 (devolução no endereço indicado na nota fiscal), podem ser apresentadas na Tabela 1.

Tabela 1 - Predisposição a devolver as embalagens

\begin{tabular}{lccrrr}
\hline & \multicolumn{2}{c}{$\begin{array}{c}\text { Devolução no endereço indicado } \\
\text { na nota fiscal }\end{array}$} & \multicolumn{3}{c}{$\begin{array}{c}\text { Devolução nos } \\
\text { revendedores }\end{array}$} \\
\hline Respostas & Frequência & Porcentagem & Frequência & Porcentagem \\
\hline 1-Discordo totalmente & 18 & 37,50 & 26 & 54,17 \\
2-Discordo & 8 & 16,67 & 1 & 2,08 \\
3-Indiferente & 13 & 27,08 & 14 & 29,17 \\
4-Concordo & 4 & 8,33 & 3 & 6,25 \\
5-Concordo totalmente & 5 & 10,42 & 4 & 8,33 \\
\hline Total & $\mathbf{4 8}$ & $\mathbf{1 0 0 , 0 0}$ & $\mathbf{4 8}$ & $\mathbf{1 0 0 , 0 0}$ \\
\hline
\end{tabular}

Fonte: os autores 
Analisando os dados acima, somando-se como negativas as respostas "discordo totalmente" e "discordo", observa-se que 26 produtores (54\%) não devolvem as embalagens nos postos de recebimento indicados nas notas fiscais de compras e 27 (56\%) não as devolvem nos revendedores onde compraram. Ficam indiferentes a essa indagação 13 ou 14 produtores. Restam 9 ou 7, ao que parece, predispostos a efetuar a devolução, cerca de no máximo $8 \%$.

As respostas dadas às questões P-12 (devolução das embalagens nos revendedores) e P-08 (devolução no endereço indicado na nota fiscal), podem ser apresentadas na Tabela 2.

Tabela 2 - Recebimento de informação sobre a obrigatoriedade da devolução das embalagens vazias e recebimento de fiscalização regular.

\begin{tabular}{lcccr}
\hline & $\begin{array}{l}\text { Recebimento de informação } \\
\text { da obrigatoriedade de } \\
\text { devolver as embalagens }\end{array}$ & $\begin{array}{l}\text { Recebimento de fiscalização } \\
\text { com regularidade }\end{array}$ \\
\hline Respostas & Frequência & Porcentagem & Frequência & Porcentagem \\
\hline 1-Discordo totalmente & 8 & 16.67 & 43 & 89.58 \\
2-Discordo & 13 & 27.08 & 1 & 2.08 \\
3-Indiferente & 3 & 6.25 & 0 & 0.00 \\
4-Concordo & 8 & 16.67 & 4 & 8.33 \\
5-Concordo & & & & 0.00 \\
totalmente & 16 & 33.33 & 0 & $\mathbf{1 0 0 . 0 0}$ \\
\hline Total & $\mathbf{4 8}$ & $\mathbf{1 0 0 . 0 0}$ & $\mathbf{4 8}$ & \\
\hline
\end{tabular}

Fonte: os autores

Atentando-se ao fato de ter informação, nota-se que a posição dos que "discordam totalmente" e "discordam" que recebem informação sobre sua obrigação de efetuar a devolução das embalagens vazias, é de 21 produtores rurais ( $44 \%$ ). Ficam na indiferença apenas 3 deles (6\%), e a maioria, 24 produtores (50\%) concordam de alguma forma que recebem informações. Os dados retratam um posicionamento até certo ponto dividido, ainda que a maioria concorda em ter recebido informações, há um percentual elevado que parece indicar que não estão sendo informados. Aliás, apenas 50\% deles concordam que receberam informações de alguma maneira.

Por outro lado, sob a perspectiva da fiscalização, a esmagadora maioria, 44 produtores (mais de $91 \%$ ) consideram não haver recebido qualquer tipo de informação e apenas $8 \%$ concordam que tenham recebido alguma fiscalização.

Analisando-se agora o tempo que o produtor demora para fazer a devolução, verifica-se a tabela 3. 


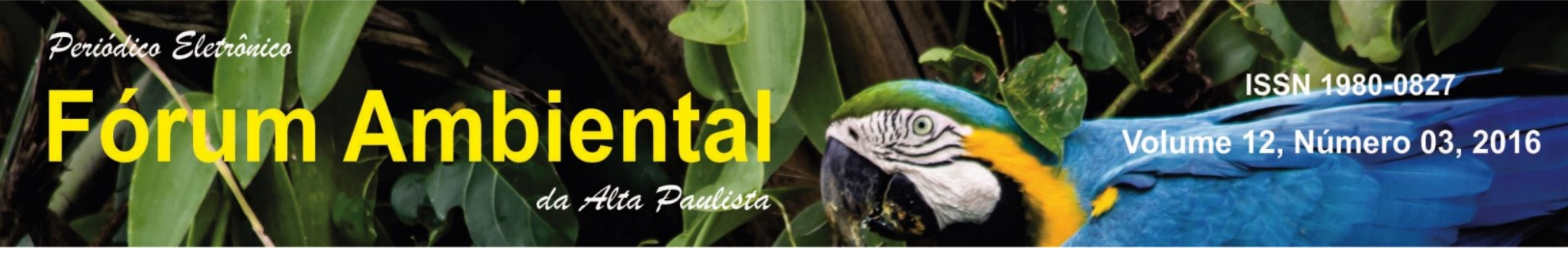

Tabela 3: De quanto em quanto tempo faço a devolução das embalagens.

\begin{tabular}{lrr}
\hline Respostas & Frequência & Porcentagem \\
\hline Até 6 meses & 3 & 6.25 \\
1 ano & 9 & 18.75 \\
2 anos & 2 & 4.17 \\
Mais de 3 anos & 2 & 4.17 \\
Não devolve & 17 & 35.42 \\
Nunca & 3 & 6.25 \\
Raramente & 1 & 2.08 \\
Varia & 11 & $\mathbf{2 2 . 9 2}$ \\
\hline Total & $\mathbf{4 8}$ & $\mathbf{1 0 0 . 0 0}$ \\
\hline
\end{tabular}

Fonte: os autores

Percebe-se que, dentro do prazo de um ano previsto na lei, apenas 11 produtores afirmam fazer a devolução (25\%). Os que afirmam categoricamente não devolver ou nunca devolver são 20 produtores (cerca de $40 \%$ ). Os demais ou afirmam devolver depois do prazo ou raramente ou em tempo variável. Considerando-se as respostas aos quesitos da Tabela 1, verifica-se conflito, eis que lá 9 ou 7 produtores afirmaram concordar com a prática da devolução, enquanto aqui são 11 que devolvem no prazo. Também 26 ou 27 produtores afirmaram "discordar ou discordar totalmente" no quesito devolver, enquanto aqui a prática de não devolver efetivamente seria de 20 produtores. Mas, tendo em vista os indiferentes daquela Tabela e os "nunca, raramente" e os passam do prazo, pode-se deduzir que a maior parte dos produtores rurais entrevistados, na realidade, não se predispõem a efetuar a devolução das embalagens vazias.

Tudo isso está relacionado com a falta de conscientização que deveria ser enfatizada em informações constantes da responsabilidade do início da logística reversa, bem como com a falta de fiscalização por parte do poder publico, que, muito embora tenha editado a lei, decretos ou regulamentos, não acompanha as atividades na prática.

Como pode ser visto, está claro a tendência maior a não devolução das embalagens vazias de agrotóxicos por meio da logística reversa, como determina a legislação, exatamente por não haver fiscalização efetiva e constante por parte do Poder Público, nem ainda conscientização por meio de informações e ou campanhas publicitárias nesse sentido.

\section{CONSIDERAÇÕES FINAIS}

O estudo apresentado endossa que há falhas na logística reversa das embalagens vazias de agrotóxicos, como já apurado por outros pesquisadores.

Ainda que a legislação seja robusta, muito bem elaborada e, por trás exista uma estrutura de coleta dessas embalagens instrumentalizada pelo INPEV, o fato é que quer por falta de estímulo, quer pela inexistência de maior estímulo nas informações divulgadas, quer pela falta 


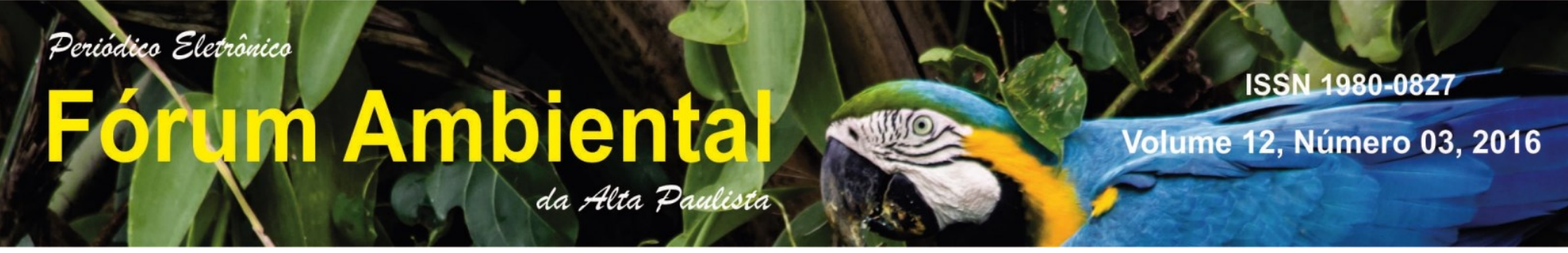

BRESSAN, Idineia; PANTALEÃO, Elba de Oliveira; SILVA; Ivana Aparecida Ferrer; OKAWADA, Fernanda Corrêa Freitas; ANDRADE, Ana Leticia Nogueira. Logística Reversa das Embalagens de Agrotóxicos: um modelo de sustentabilidade. XVI ENGEMA, 2014. Disponível em < http://www.engema.org.br/XVIENGEMA/392.pdf > Acesso em 31 ago. 2015

CANTOS, Clotilde; MIRANDA, Zoraide Amarante I.; LICCO, Eduardo Antonio. Contribuições para a Gestão das Embalagens Vazias de Agrotóxicos. INTERFACEHS - Revista de Gestão Integrada em Saúde do Trabalho e Meio Ambiente - v.3, n.2, Seção Interfacehs 1, abr./ agosto. 2008 Disponível em <www.interfacehs.sp.senac.br>. Acesso em 31 ago. 2015

CERVO, Amado Luiz; BERVIAN, Pedro Alcino. Metodologia científica. São Paulo: Prentice Hall, 2003.

COMETTI, José Luís Said. Logística reversa das embalagens de agrotóxicos no Brasil: um caminho sustentável?. 2009. 152 f., il. Dissertação (Mestrado em Desenvolvimento Sustentável)-Universidade de Brasília, 2009.

COMETTI, José Luís Said; ALVES, Isabel Teresa Gama. Responsabilização Pós-Consumo e Logística Reversa: O Caso das Embalagens de Agrotóxicos no Brasil. Revista Sustentabilidade em Debate. 2010

FARIA, Ana Cristina de; PEREIRA, Raquel da Silva. O Processo de Logística Reversa de Embalagens de Agrotóxicos: um estudo de caso sobre o INPEV. Organizações Rurais \& Agroindustriais, Lavras, v. 14, n. 1, p. 127-141, 2012

FREITAS, Michele Medianeira Martins; HOPPE, Jaqueline Hintz; MURINI, Lisandra Taschetto. A logística Reversa das Embalagens de Defensivos em uma Cooperativa Agrícola. Revista em Agronegócio e Meio Ambiente, Maringá (PR), v. 8. N. Edição Especial, p. 181-203, jan/abr. 2015

GRUTZMACHER, Douglas Daniel et al. Embalagens Vazias de Agrotóxicos: organização dos fabricantes e suas obrigações (Lei Federal 9.974). R. Bras. Agrociência, Pelotas, v. 12, n. 1, p. 05-06, jan-mar, 2006.

INPEV - Relatório de Sustentabilidade 2014. Disponível em < http://www.inpev.org.br/relatorio-sustentabilidade/2014/pt/index.html> Acesso em: 02 nov. 2015

LEITE, Paulo Roberto. Logística Reversa: meio ambiente e competitividade. 2 ed. São Paulo: Pearson, 2009.

LEITE, Paulo Roberto. Logística Reversa: meio ambiente e competitividade. São Paulo: Prentice Hall, 2003.

MARCONI, Marina de Andrade; LAKATOS, Eva Maria. Metodologia Científica. 4ạ. ed. São Paulo: Editora Atlas, 2004.

MARQUES, Mauricio Dias; BRAGA JUNIOR, Sergio Silva; CATANEO, Pedro Fernando. Discussao da estrutura formal sobre o retorno das embalagens de agrotoxicos: uma revisao teorica sob 


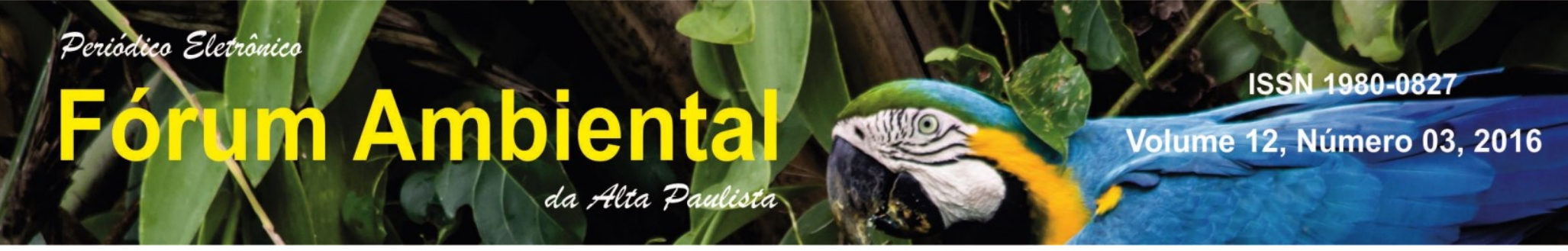

os aspectos legais e da consciencia ambiental. Periódico Eletrônico Fórum Ambiental da Alta Paulista, XI Fórum Ambiental da Alta Paulista, v. 11, n. 2, 2015, pp. 30-56.

MELO, Wederson Miranda et al. Logística Reversa de Embalagens de Agrotóxicos: um estudo de caso na cidade de Patos-MG. VIII Congresso Nacional de Excelência em Gestão, 8 e 9 de junho de 2012. ISSN 1984-9354

MOURÃO, Renata Fernandes; SEO, Emília Satoshi Miyamaru. Logística reversa de lâmpadas fluorescentes. InterfacEHS Revista de Saúde, Meio Ambiente e Sustentabilidade. V. 7, N. 3, 2012

Organização Pan-Americana da Saúde/Organização Mundial da Saúde (OPAS/OMS). Manual de Vigilância da Saúde de Populações Expostas a Agrotóxicos. Disponível em: <

http://bvsms.saude.gov.br/bvs/publicacoes/livro2.pdf>. Acesso em: 01 jul. 2015.

SEHNEM, Simone; SIMIONI, Elisete; CHIESA, Jaqueline. Logística Reversa de Embalagens de Agrotóxicos e a Redução do Impacto Ambiental. Pretexto, Belo Horizonte, v. 10, n. 3, p. 47-60, $\mathrm{jul} / \mathrm{set} / 2009$

SHIBAO, Fábio Ytoshi; MOORI, Roberto Giro; SANTOS, Mário Roberto dos. A logística reversa e as embalagens vazias de defensivos agrícolas no Brasil. In: XVIII Simpósio de Engenharia de Produção, XVIII, 2010, Bauru. Anais, São Paulo.

SOUZA, Valéria Nogueira de; GEBLER, Luciano. Análise de cenário envolvendo embalagens vazias de agrotóxicos originadas da cultura da macieira. Pesticidas: R. Ecotoxico e mio ambiente, Curitiba, v. 23, p. 75-82, jan/dez. 2013 